\title{
Dorsal spinal epidural psammomatous meningioma in an adult male
}

\author{
Sharad Pandey, Kulwant Singh, Vivek Sharma, Amrita Ghosh ${ }^{1}$, Saurabh Suman ${ }^{2}$ \\ Departments of Neuro Surgery, ${ }^{1}$ Pathology and ${ }^{2}$ Anaesthesia, Sir Sunderlal Hospital, Institute of Medical Science, Banaras Hindu University, \\ Varanasi, Uttar Pradesh, India
}

\begin{abstract}
Meningiomas are benign in nature and arise from the arachnoid cells. They are mostly situated in the intracranial compartment, whereas spinal meningiomas are rare. Approximately, in 10\% of cases, an extradural component is seen but an exclusively extradural meningioma is quite uncommon. However, WHO Grade II (atypical) and Grade III (anaplastic) tumors can behave aggressively. We reported a case of purely extradural psammomatous meningioma in an adult male affecting the dorsal spine although uncommon meningiomas should be included in the differential diagnosis of extradural intraspinal masses.
\end{abstract}

Key words: Dorsal spine, extradural, intraspinal, psammomatous meningioma

\section{Introduction}

Approximately, $1.2 \%$ of all meningiomas of the central nervous system affect the spine, being relatively rare compared to those in the intracranial compartment. Further, isolated extradural spinal meningiomas are exceedingly rare. ${ }^{[1,2]}$ Thus are seldom considered in the differential diagnosis of spinal extradural lesions. ${ }^{[3]}$ We are reporting a case of purely extradural psammomatous meningioma affecting the dorsal spine. It is important to emphasize that to reach the definitive diagnosis of extra-axial soft tissue lesions and properly manage the patient, histopathological examination, and frozen section biopsy are required.

\section{Case Report}

An 18-year-old adult male presented at the Neurosurgery Outpatient Department with chief complaints of gradually

Address for correspondence:

Dr. Sharad Pandey, Department of Neuro Surgery, Sir Sunderlal Hospital, Institute of Medical Science, Banaras Hindu University, Varanasi - 221 005, Uttar Pradesh, India.

E-mail: drsharad23@yahoo.com

\begin{tabular}{|l|l|}
\hline \multicolumn{2}{|c|}{ Access this article online } \\
\hline Quick Response Code: & Website: \\
\hline & www.ruralneuropractice.com \\
\cline { 2 - 2 } & \\
\hline$\square$ & \\
\hline
\end{tabular}

progressing weakness and diminished sensation in both the lower limbs of 1 year duration. Ten months later, he started experiencing constipation and urinary incontinence. These complaints were preceded by pain in the dorsal spine. His lower limb weakness progressed, and he became bed ridden. There was no history of fever, trauma, or any chronic illness. On physical examination, spastic paraplegia and loss of all sensory modalities below the D7 dermatome were found. On gadolinium enhanced magnetic resonance imaging of the dorsal spine, an extradural spinal lesion extending from midbody of D7 to midbody of D9 vertebra [Figure 1], which was hypointense on T1 and T2 [Figure 2] with homogenous enhancement with contrast was seen posterior and lateral to the spinal cord compressing the dura anteriorly, and extending to the left D8-D9 neural foramina, thus with features suggestive of either neurofibroma or meningioma [Figure 3]. The patient was planned for elective surgery and underwent D7-D9 laminectomy and total excision of the lesion. Intraoperatively, it was a vascular lesion which was adherent to the dura mater [Figure 4]. Histopathological examination

This is an open access article distributed under the terms of the Creative Commons Attribution-NonCommercial-ShareAlike 3.0 License, which allows others to remix, tweak, and build upon the work non-commercially, as long as the author is credited and the new creations are licensed under the identical terms.

For reprints contact: reprints@medknow.com

How to cite this article: Pandey S, Singh K, Sharma V, Ghosh A, Suman S. Dorsal spinal epidural psammomatous meningioma in an adult male. J Neurosci Rural Pract 2016;7:125-7. 
reported features suggestive of psammomatous meningioma [Figure 5]. The patient improved in the postoperative period and regained Grade $5 / 5$ power in both lower limbs, sensations, and bowel and bladder function improved at 6 months follow-up.

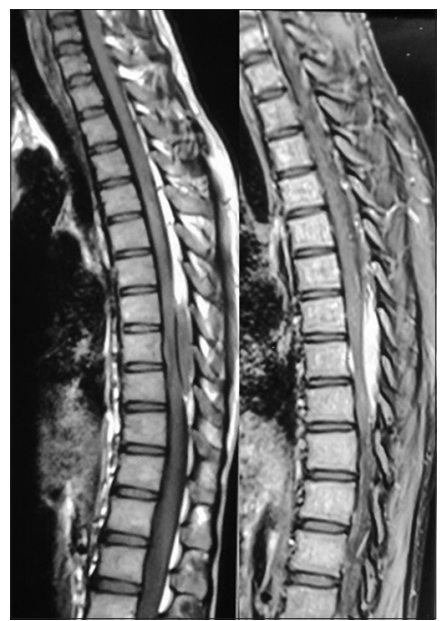

Figure 1: MRI of the dorsal spine, an extradural spinal lesion extending from midbody of D7 to midbody of D9 vertebra (plane and contrast)

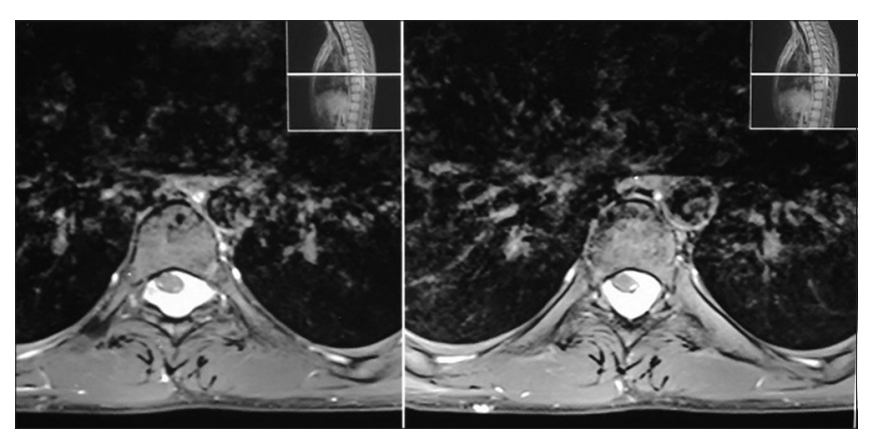

Figure 3: MRI of the dorsal spine, showing an extradural spinal lesion with homogenous enhancement with contrast

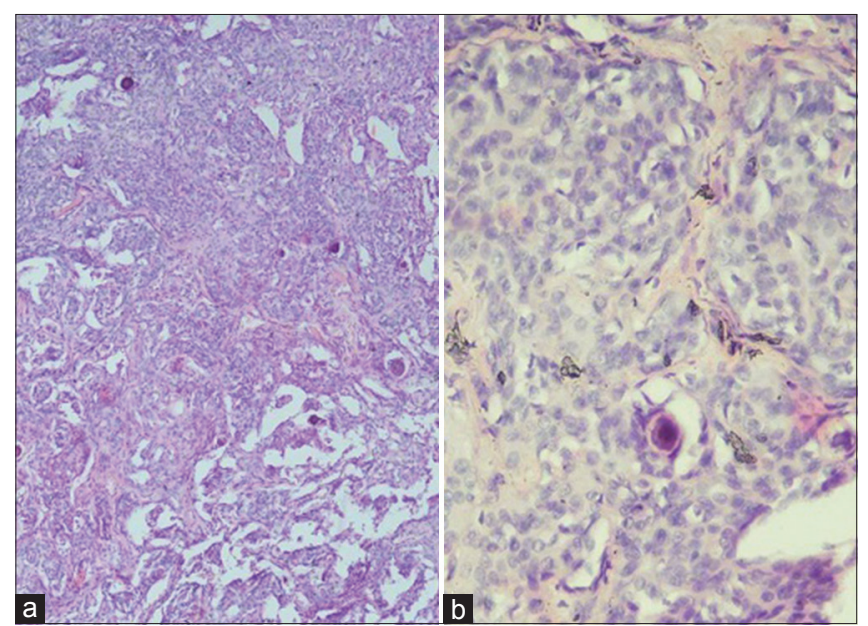

Figure 5: (a) Histopathological examination showing sheets of meningothelial cells showing whirling pattern focally $(\times 40)$. (b) Magnified view of tumour showing syncytial sheets of meningothelial cells, with psammoma bodies on HPE $(\times 200)$

\section{Discussion}

Meningiomas are benign in nature and arise from the arachnoid cells. They are mostly situated in the intracranial compartment, whereas spinal meningiomas are rare. Spinal meningiomas comprise approximately $1.2 \%$ of all the meningiomas and $25 \%$ of all the spinal cord tumors. ${ }^{[4,5]}$ These tumors show female predominance with a male: female ratio of 1:9, with no sex predilection in children. ${ }^{[6]}$ Approximately, in $10 \%$ of cases, an extradural component is seen but an exclusively extradural meningioma is quite uncommon. ${ }^{[3]}$

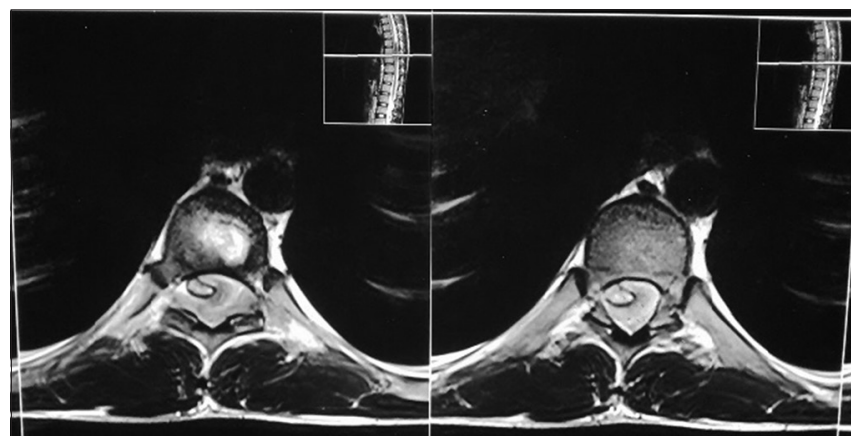

Figure 2: MRI of the dorsal spine, showing an extradural spinal lesion hypointense on T1 and T2 images

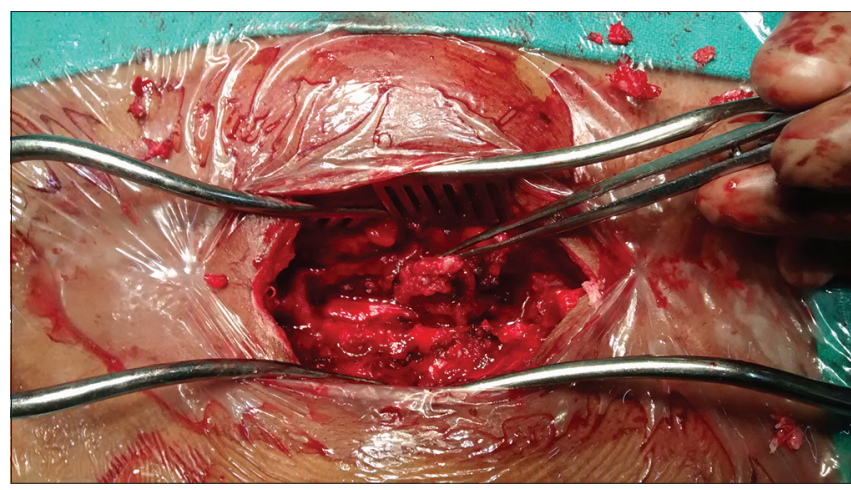

Figure 4: Intraoperative photograph showing a vascular lesion adherent to the dura mater

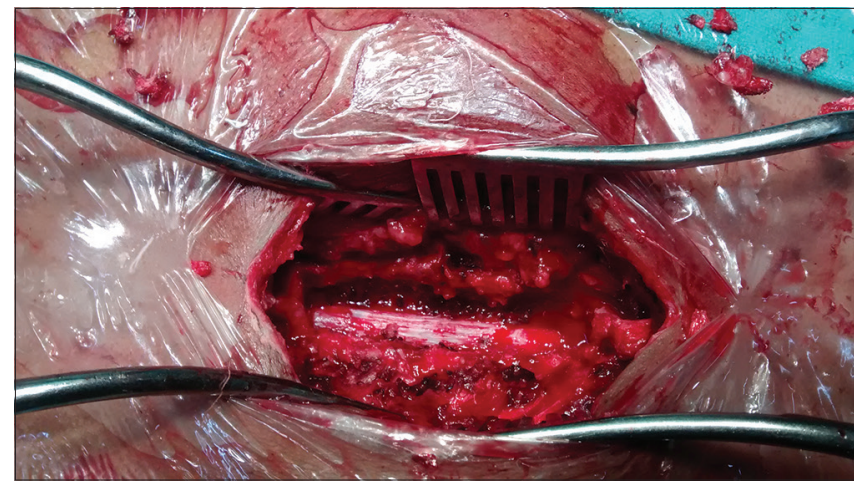

Figure 6: Intraoperativel photograph showing, shining-white dura after striping off the tumor 
These tumors are attributed to the presence of ectopic or separated arachnoid tissue around the periradicular nerve root sleeve, where the spinal leptomeninges merge directly into the dura mater. ${ }^{[3]}$

It is pertinent to be aware of the fact that totally extradural spinal meningiomas, especially the "en plaque" variety may mimic metastatic disease. ${ }^{[7]}$ This can be ruled out by an intraoperative histology, i.e., frozen section histopathology, which is a must for optimal surgical decision-making. In this case, intraoperative frozen section enabled us to correctly identify the pathology and perform the near-total resection. After the intraoperative diagnosis of meningioma is confirmed for an extradural spinal lesion, gross total resection of the tumor including extensions into the bone or the paraspinal space should be conducted. This approach is likely to give the best results since the prognosis of this tumor depends on the extent of resection. ${ }^{[7]}$

Intraoperatively, we were able to strip off the tumor from the spinal dura, without excising the dura to expose the shining white dura underneath [Figure 6], as these extradural spinal meningiomas arise from the dural root sleeve and not from the external surface of the spinal dura. Most meningiomas are benign, well-circumscribed, slow growing tumors, and behave mostly according to the pathological (WHO) grading and usually follow an uneventful clinical course. However, theWHOGrade II (atypical) and Grade III (anaplastic) tumors can behave aggressively clinically and histologically. ${ }^{[8]}$ Bony involvement and paraspinal extent are responsible for the worse prognoses due to difficult removal. ${ }^{[7]}$
To conclude, meningiomas should be included in the differential diagnosis of extradural intraspinal masses. Intraoperative pathological examination helps in further management. Although benign, but it is necessary to conduct long-term clinical and radiological follow-up to diagnose recurrence.

\section{Financial support and sponsorship \\ Nil.}

\section{Conflicts of interest}

There are no conflicts of interest.

\section{References}

1. Gezen F, Kahraman S, Canakci Z, Bedük A. Review of 36 cases of spinal cord meningioma. Spine (Phila Pa 1976) 2000;25:727-31.

2. Weil SM, Gewirtz RJ, Tew JM Jr. Concurrent intradural and extradural meningiomas of the cervical spine. Neurosurgery 1990;27:629-31.

3. Zevgaridis D, Thomé C. Purely epidural spinal meningioma mimicking metastatic tumor: Case report and review of the literature. Spine (Phila Pa 1976) 2002;27:E403-5.

4. Levy WJ Jr, Bay J, Dohn D. Spinal cord meningioma. J Neurosurg 1982;57:804-12.

5. Solero CL, Fornari M, Giombini S, Lasio G, Oliveri G, Cimino C, et al. Spinal meningiomas: Review of 174 operated cases. Neurosurgery 1989;25:153-60.

6. Peker S, Cerçi A, Ozgen S, Isik N, Kalelioglu M, Pamir MN. Spinal meningiomas: Evaluation of 41 patients. J Neurosurg Sci 2005;49:7-11.

7. Frank BL, Harrop JS, Hanna A, Ratliff J. Cervical extradural meningioma: Case report and literature review. J Spinal Cord Med 2008;31:302-5.

8. Liu Y, Chotai S, Chen M, Jin S, Qi ST, Pan J. Preoperative radiologic classification of convexity meningioma to predict the survival and aggressive meningioma behavior. PLoS One 2015;10:e0118908. 